\title{
28 Research Soure \\ Predictive modeling of hospital Length of Stay in COVID-19 patients using Artificial Neural Networks
}

\author{
Azam Orooji \\ North Khorasan University of Medical Science (NKUMS) \\ Mostafa Shanbehzadeh \\ Ilam University of Medical Sciences \\ Hadi Kazemi-Arpanahi ( $\sim$ H.kazemi@abadanums.ac.ir) \\ Abadan Faculty of Medical Sciences \\ Mohsen Shafiee \\ Abadan Faculty of Medical Sciences
}

\section{Research Article}

Keywords: COVID-19, Coronavirus, Artificial neural networks, Machine learning, Length of Stay

Posted Date: November 30th, 2021

DOI: https://doi.org/10.21203/rs.3.rs-1024483/v1

License: (9) This work is licensed under a Creative Commons Attribution 4.0 International License.

Read Full License 


\section{Abstract}

\section{Background}

The current pandemic of coronavirus disease (COVID-19) causes unexpected economic burdens to worldwide health organizations with severe shortages in hospital bed capacity and other related medical resources. Therefore, predicting the length of stay (LOS) is essential to ensure optimal allocating scarce hospital resources and inform evidence-based decision-making. Thus, the purpose of this research is to construct a model for predicting COVID-19 patients' hospital LOS by multiple multilayer perceptronartificial neural network (MLP-ANN) algorithms.

Material and Methods

Using a single-center registry, the records of 1225 laboratory-confirmed COVID-19 hospitalized cases from February 9, 2020, to December 20, 2020, were analyzed. The correlation coefficient technique was developed to determine the most significant variables as the input of the ANN models. Only variables with a correlation coefficient at the P-value $<0.2$ were used in model construction. Ultimately the prediction models were developed based on 12 ANN techniques according to selected variables.

Results

After implementing feature selection, a total of 20 variables was determined as the most relevant predictors to build the models. The results indicated that the best performance belongs to a neural network with 20 and 10 neurons in the hidden layer of the Bayesian Regularization classifier for whole and selected features with RMSE of 1.6213 and 2.2332 , respectively.

\section{Conclusion}

The developed model in this study can help in the better calculation of LOS in COVID-19 patients. This model also can be leveraged in hospital bed management and optimized resource utilization.

\section{Background}

The 2019 coronavirus disease (COVID-19) is a very contagious viral infection and thus far remains to be spread aggressively widespread and has become a serious international health problem. The COVID-19 rapid outbreak exposure healthcare organizations with the scarcity of hospital resources and overtiredness of frontline healthcare workers (1-6). Clinical manifestations so far presented substantial heterogeneity among different patients and ranging from asymptomatic, or mild flu-like symptoms, to severe respiratory illness and pneumonia, ICU hospitalization, multi-organ failure, and ultimately death (7). The COVID-19 high transmission rates, unknown clinical patterns coupled with a long incubation period put a lot of pressure on healthcare organizations by rapidly increasing demands for healthcare services and the surge in hospitalization volumes (8). It highlights the need for objective and evidence- 
based solutions for the effective use of medical facilities available in hospitals (e.g. hospital beds, respiratory ventilators, etc.) to prevent hospital overwhelming and optimal use of healthcare resources(9).

For this purpose, accurate forecasting of the COVID-19 hospital length of stay (LOS) and the determination of influencing factors would be pivotal to optimal management and utilization of limited hospital resources. In addition, by predicting the LOS metrics, health care organizations could redesign their clinical pathways and recognize the bottlenecks for maximizing the use of medical resources (1012).

As the pandemic worsens, identifying the resulting needs of patients and service providers has become a vital prerequisite. It needs anticipation of how long each case will need inpatient services $(13,14)$. An exact approximation of the patients' LOS would be of substantial worth for scientifically dealing with both medical resources and the distribution of caregivers $(8,15)$. During the COVID-19 epidemic, predicting the average LOS has become significantly critical for hospital staffing, resource allocation, and appointment scheduling $(15,16)$.

In this situation, as overwhelmed health systems endeavor to escalate resource utilization and eliminate bottlenecks of patient hospitalization, adopting data-driven machine learning $(\mathrm{ML})$ solutions will be useful(17). ML is a branch of artificial intelligence (Al) that can apply to analysis and inference in a large volume of retrospective datasets to extract distinctive associations or make known unfamiliar patterns with minimal human intervention or any programming design $(18,19)$. Evermore, ML techniques can employ in medical practice to increase prognostic modeling and reveal new contributing factors of a specific target outcome to predict future or obscure trends $(20,21)$.

Artificial Neural Networks (ANNs) is a supervised ML technique that imitates the tasks of biological human neurons based on a collection of connected nodes (input-hidden-output) called artificial neurons $(22,23)$. This method can be trained to recognize and categorize complex patterns of diseases and related healthcare events through an iterative learning process. So far, there are multiple ANN solutions were presented for LOS prediction and determining its affecting factors $(10,24-28)$.

Towards this aim, we established and tested an intelligent model using ANN algorithms to predict COVID19 LOS according to routine clinical data at admission time. Generally, we are looking for answers to these questions: 1- what are the most important clinical predictors or variables affecting the COVID-19 hospital LOS? and 2- "what is the best ANN algorithm for prediction of LOS?

\section{Material And Methods}

This is a retrospective, single-center, and cross-sectional study, that was conducted in 2021 for predicting the COVID-19 patients LOS based on selected data-driven ANN techniques. It was conducted in five stages, including, 1- data set description and participants, 2- data preparation, 3- feature reduction, 4model development, and 5- model evaluation. 


\subsection{Data set description and participants}

In this study, a COVID-19 hospital-based registry database from Ayatollah Taleghani hospital, Abadan city, Iran, was retrospectively reviewed. Only COVID-19 patients with positive real-time reversetranscriptase PCR (RT-PCR) test admitted from January 9, 2020, until January 20, 2021, met our inclusion criteria to be included in this study. During this period, a total of 12885 suspected cases with COVID-19 have been referred to Ayatollah Taleghani hospital ambulatory and Emergency Departments (EDs). Of those, 3350 cases were introduced as confirmed COVID-19 by RT-PCR test. After applying the inclusion/ exclusion criteria, finally, 1225 records were entered in the study (Figure 1).

The exclusion criteria for patient selection were:

1) Non-COVID-19 cases or non-hospitalized COVID-19 or patients with unknown disposition

2) Patients who were less than 18 years of age

3) Incomplete case records (missing more than $70 \%$ )

4) Admission time before January 9, 2020, or after January 20, 2021.

The included cases are defined based on 53 risk factors in five main classes including patients' demographics (five variables), clinical manifestations (14 variables), comorbidities (seven variables), laboratory (26 variables), and treatment (one variable) (Table 1). To protect privacy and confidentiality, we concealed the unique identifying information of all patients in the process of data collection and presentation.

Table1. Baseline predictor variables and outcomes measures 


\begin{tabular}{|ll|}
\hline Data Classes & Risk factors \\
\hline Demographical & Gender, age, weight, height, and blood type \\
\hline $\begin{array}{l}\text { Clinical } \\
\text { manifestations }\end{array}$ & $\begin{array}{l}\text { Cough, contusion, nausea, vomit, headache, gastrointestinal (GI) symptoms, } \\
\text { muscular pain, chill, fever, dyspnea, loss of taste, loss of smell, runny nose, and } \\
\text { sore throat }\end{array}$ \\
\hline $\begin{array}{l}\text { comorbidities } \\
\text { diseases }\end{array}$ & $\begin{array}{l}\text { Pneumonia, cardiac disease, hypertension, diabetes, smoking, alcohol addiction, } \\
\text { and another underline disease }\end{array}$ \\
\hline $\begin{array}{l}\text { Laboratory } \\
\text { data }\end{array}$ & $\begin{array}{l}\text { Creatinine, red-cell count, white cell count, hematocrit, hemoglobin, platelet count, } \\
\text { absolute lymphocyte count, absolute neutrophil count, calcium, phosphorus, } \\
\text { magnesium, sodium, potassium, blood urea nitrogen(BUN), total bilirubin, } \\
\text { aspartate aminotransferase(ASP), alanine aminotransferase(ALT), albumin, } \\
\text { glucose, lactate dehydrogenase(LDH), activated partial, thromboplastin time, } \\
\text { prothrombin time, alkaline phosphatase, erythrocyte sedimentation rate(ESR), C- } \\
\text { reactive protein, hypersensitive troponin }\end{array}$ \\
\hline Treatment & \begin{tabular}{l} 
Oxygen therapy \\
\hline Outcome
\end{tabular} \\
\hline
\end{tabular}

\subsection{Data preparation}

Incomplete case records which had a lot of missing data (more than 70\%) were excluded from the analysis. Also, the remaining missing values were imputed with the mean or mode of each variable. Noisy and abnormal values, errors, duplicates, and meaningless data were checked by researchers in collaboration with two infectious diseases specialists and hematologists. For different interpretations about data preprocessing, we contacted the corresponding physicians.

\subsection{Feature reduction}

Feature selection or variable selection is an effective technique that is used to determine the most meaningful variables, reduce the dimensions of the dataset and improve the efficiency of $\mathrm{ML}$ algorithms (29). In this study, the variables with a correlation coefficient value less than 0.2 (P-value <0.2) were identified as effective risk factors in predicting the LOS of COVID-19 patients and included in the ANNs model.

\subsection{Model development}

Artificial Neural Networks (ANNs) is a set of computing algorithms that emulate the functions of biological neural networks. The components of the models are nodes, weights, and layers (input, hidden, and output layers) (41). Multilayer perceptron-ANN (MLP-ANN) is the simplest and most commonly used ANN architecture due to its structural flexibility, good representational capabilities, and a large number of trainable algorithms $(30,31)$. 
In this study, several MLP-ANN methods including Levenberg-Marquardt(32), Bayesian Regularization(33), BFGS quasi Newton backpropagation(34), Resilient Backpropagation(35), Scaled Conjugate Gradient(36), Conjugate Gradient with Powell/ Beale Restarts(37), Fletcher-Powell Conjugate Gradient(38), Polak-Ribiére Conjugate Gradient(39), One Step Secant(40), Variable Learning Rate Gradient Descent(41), Gradient Descent with Momentum and Gradient Descent(42) were designed based on trialand-error methods with different configurations. The structure of neural networks was changed by changing the number of hidden layers neurons from 5 to 30 and using 12 different learning algorithms (see Table 2). All simulations were implemented in two datasets: 1- the main dataset including 53 risk factors and 2- the derived dataset after conducting feature selection. The LOS was also considered as output.

Table 2. Selected ANN algorithms brief description 


\begin{tabular}{|c|c|c|c|}
\hline Train algorithm & $\begin{array}{l}\text { MatLab } \\
\text { function }\end{array}$ & $\begin{array}{l}\text { Maximum number of } \\
\text { epochs to train }\end{array}$ & Other parameters \\
\hline Levenberg-Marquardt & trainlm & 1000 & Mu: 0.001 \\
\hline Bayesian Regularization & trainbr & 1000 & Mu: 0.005 \\
\hline \multirow[t]{2}{*}{$\begin{array}{l}\text { BFGS quasi-Newton } \\
\text { backpropagation }\end{array}$} & \multirow[t]{2}{*}{ trainbfg } & \multirow[t]{2}{*}{1000} & $\begin{array}{l}\text { Name of the line search } \\
\text { routine to use=srchcha }\end{array}$ \\
\hline & & & initial step size=0.01 \\
\hline Resilient Backpropagation & trainrp & 1000 & learning rate= 0.01 \\
\hline Scaled Conjugate Gradient & Trainscg & 1000 & \\
\hline \multirow[t]{2}{*}{$\begin{array}{l}\text { Conjugate Gradient with } \\
\text { Powell/Beale Restarts }\end{array}$} & \multirow[t]{2}{*}{ Traincgb } & \multirow[t]{2}{*}{1000} & $\begin{array}{l}\text { Name of the line search } \\
\text { routine to use=srchcha }\end{array}$ \\
\hline & & & initial step size=0.01 \\
\hline \multirow[t]{2}{*}{$\begin{array}{l}\text { Fletcher-Powell Conjugate } \\
\text { Gradient }\end{array}$} & \multirow[t]{2}{*}{ Traincgf } & \multirow[t]{2}{*}{1000} & $\begin{array}{l}\text { Name of the line search } \\
\text { routine to use=srchcha }\end{array}$ \\
\hline & & & initial step size=0.01 \\
\hline \multirow[t]{2}{*}{$\begin{array}{l}\text { Polak-Ribiére Conjugate } \\
\text { Gradient }\end{array}$} & \multirow[t]{2}{*}{ Traincgp } & \multirow[t]{2}{*}{1000} & $\begin{array}{l}\text { Name of the line search } \\
\text { routine to use=srchcha }\end{array}$ \\
\hline & & & initial step size=0.01 \\
\hline \multirow[t]{2}{*}{ One Step Secant } & \multirow[t]{2}{*}{ trainoss } & \multirow[t]{2}{*}{1000} & $\begin{array}{l}\text { Name of the line search } \\
\text { routine to use=srchcha }\end{array}$ \\
\hline & & & initial step size=0.01 \\
\hline \multirow{2}{*}{$\begin{array}{l}\text { Variable Learning Rate } \\
\text { Gradient Descent }\end{array}$} & \multirow[t]{2}{*}{ traingdx } & \multirow[t]{2}{*}{1000} & learning rate= 0.01 \\
\hline & & & Momentum constant $=0.9$ \\
\hline \multirow{2}{*}{$\begin{array}{l}\text { Gradient Descent with } \\
\text { Momentum }\end{array}$} & \multirow[t]{2}{*}{ traingdm } & \multirow[t]{2}{*}{1000} & learning rate=0.01 \\
\hline & & & Momentum constant $=0.9$ \\
\hline Gradient Descent & traingd & 1000 & learning rate=0.01 \\
\hline
\end{tabular}

\section{5 Model evaluation}

According to the performance evaluation of the models by 10 times, and each time randomly the dataset was divided into a test $(30 \%)$ and training $(70 \%)$ classes. Then, the networks were evaluated by RootMean-Square Error (RMSE) 10 times.

\section{Results}


After applying the exclusion criteria, finally, a total of 1225 patients met eligibilities (see Figure 1 ). Of 1225 hospitalized COVID-19 patients, 664(54.20\%) were male and 561 (45.80\%) were women and the median age of participants was 57.25 (interquartile 18-100). 170 (13.87\%) were hospitalized in ICU and 1055 (86.13\%) were hospitalized in general wards. Of these, 1136 (92.75\%) were recovered and 89 (7.25\%) were deceased. Descriptive statistics for the 1225 records in this dataset are shown in Table 3. 
Table 3

The descriptive statistics of variables of the study after preprocessing

\begin{tabular}{|lll|}
\hline Qualitative variables & Values & Frequencies \\
\hline Blood Type & A- & 17 \\
& At & 552 \\
& B- & 13 \\
& B+ & 126 \\
\hline & O- & 29 \\
\hline O+ & 421 \\
\hline Gender & AB- & 6 \\
\hline Cough & AB+ & 61 \\
\hline Contusion & Male, Female & 664,561 \\
\hline Nausea & Yes, No & 958,267 \\
\hline Vomit & Yes, No & 409,816 \\
\hline Headache & Yes, No & 401,824 \\
\hline Gastrointestinal symptoms & Yes, No & 346,879 \\
\hline Muscular pain & Yes, No & 312,913 \\
\hline Chill & Yes, No & 252,973 \\
\hline Fever & Yes, No & 623,602 \\
\hline Pneumonia & Yes, No & 591,634 \\
\hline Oxygen therapy & Yes, No & 628,597 \\
\hline Dyspnea & Yes, No & 1044,181 \\
\hline Loss of taste & Yes, No & 1053,172 \\
\hline Loss of smell & Yes, No & 1078,147 \\
\hline Yunny Noise & Yes, No & 272,953 \\
\hline Sore throat & 305,920 \\
\hline
\end{tabular}




\begin{tabular}{|c|c|c|}
\hline Qualitative variables & Values & Frequencies \\
\hline Hypertension & Yes, No & 395,830 \\
\hline Diabetes & Yes, No & 268,957 \\
\hline Smoking & Yes, No & 41,1184 \\
\hline alcohol addiction & Yes, No & 11,1214 \\
\hline C-reactive protein & Positive, Negative & 1063,162 \\
\hline Hypersensitive troponin & Positive, Negative & 58,1167 \\
\hline ICU admission (Outcome) & Yes, No & 1055,170 \\
\hline Quantitative variables & Range & Mean (SD) \\
\hline Age (year) & $18-100$ & $57.25(17.8)$ \\
\hline Height & $92-195$ & $168.53(8.5)$ \\
\hline Weight & $6.5-163$ & $75.20(13.0)$ \\
\hline Creatinine & $0.1-17.9$ & $1.39(1.4)$ \\
\hline Red-cell count & $1.38-13.1$ & $4.56(0.9)$ \\
\hline White-cell count & $1300-63000$ & 8182.34 (4897.4) \\
\hline Hematocrit & $3.6-73.9$ & $39.20(6.7)$ \\
\hline Hemoglobin & $3.7-46$ & $13.21(2.4)$ \\
\hline Platelet count & $108000-691000$ & $215493.66(88380.1)$ \\
\hline Absolute lymphocyte count & $2-95$ & $23.74(11.8)$ \\
\hline Absolute neutrophil count & $8-98$ & $74.52(12.3)$ \\
\hline Calcium & $0.9-14.1$ & $9.68(0.8)$ \\
\hline Phosphorus & $2-12.4$ & $3.50(0.5)$ \\
\hline Magnesium & $1.14-19.1$ & $2.16(0.6)$ \\
\hline Sodium & $37-157$ & $137.94(5.3)$ \\
\hline Potassium & $2.5-14.2$ & $3.98(0.7)$ \\
\hline Blood urea nitrogen & $0.5-251$ & $42.52(31.7)$ \\
\hline Total bilirubin & $0.01-10$ & $0.72(0.7)$ \\
\hline Aspartate aminotransferase & 3.8-924 & $44.45(53.5)$ \\
\hline Alanine aminotransferase & $2-672$ & $38.29(41.6)$ \\
\hline
\end{tabular}




\begin{tabular}{|lll|}
\hline Qualitative variables & Values & Frequencies \\
\hline Albumin & $0.2-8.9$ & $4.02(0.5)$ \\
\hline Glucose & $18-994$ & $136.09(74.2)$ \\
\hline Lactate dehydrogenase & $4.6-6973$ & $555.68(339.0)$ \\
\hline Activated partial thromboplastin time & $1-120$ & $28.56(11.4)$ \\
\hline Prothrombin time & $0.9-46.8$ & $12.82(1.9)$ \\
\hline Alkaline phosphatase & $9.6-2846$ & $213.12(139.2)$ \\
\hline Erythrocyte sedimentation rate & $2-258$ & $40.65(28.8)$ \\
\hline
\end{tabular}

\subsection{Variables included in the ANN models}

The results of feature selection for determining the most important diagnostic criteria affecting COVID-19 hospital LOS based on the correlation coefficient at $\mathrm{P}<0.2$ have been demonstrated in Table4.

Table4. The key diagnostic criteria at the $\mathrm{P}<0.2$ 


\begin{tabular}{|c|c|c|c|c|c|}
\hline Variables & $\begin{array}{l}\text { Pearson } \\
\text { Correlation }\end{array}$ & $\begin{array}{l}P- \\
\text { value }\end{array}$ & Variables & $\begin{array}{l}\text { Pearson } \\
\text { Correlation }\end{array}$ & P-value \\
\hline Age & -.045 & *.119 & Blood Type & -0.025128 & .274 \\
\hline Height & -0.24 & .409 & Sex & -.107 & .380 \\
\hline Weight & -0.25 & .388 & Cough & .299 & *0.041417 \\
\hline Temperature & -0.32 & .268 & Contusion & -.122 & .342 \\
\hline Creatinine & -.066 & *.019 & Hypertension & -.1744378 & $\star 0.0541$ \\
\hline Red-cell count & .029 & .315 & $\begin{array}{l}\text { Cardiovascular } \\
\text { disorders }\end{array}$ & .2746594 & *0.125 \\
\hline White-cell count & -.054 & *.057 & Alcohol consumption & .7923469 & 0.218 \\
\hline Hematocrit & -.017 & .562 & Smoking & .3123146 & 0.354 \\
\hline Hemoglobin & -0.10 & .724 & Diabetes & .0980716 & *0.104 \\
\hline Platelet count & .018 & .532 & $\begin{array}{l}\text { Other underline } \\
\text { disorders }\end{array}$ & .0904762 & 0.465 \\
\hline $\begin{array}{l}\text { Absolute lymphocyte } \\
\text { count }\end{array}$ & -.057 & *.044 & Sore throat & .0591151 & 0.640 \\
\hline $\begin{array}{l}\text { Absolute neutrophil } \\
\text { count }\end{array}$ & .061 & *.033 & Runny noise & -.1446846 & 0.253 \\
\hline Calcium & -.055 & *.055 & Loss of smell & .0335175 & 0.811 \\
\hline Phosphorus & -.020 & .476 & Loss of taste & -.1192558 & 0.414 \\
\hline Magnesium & -.033 & .243 & Dyspnea & .4443414 & *0.017 \\
\hline Sodium & -.015 & .590 & Oxygen therapy & .460136 & *0.008 \\
\hline Potassium & .015 & .607 & Pneumonia & .2690936 & *0.115 \\
\hline $\begin{array}{l}\text { Blood urea nitrogen } \\
\text { (BUN) }\end{array}$ & -.059 & *.038 & Fever & .0241734 & 0.842 \\
\hline Total bilirubin & -.003 & .915 & Chill & .0269847 & 0.824 \\
\hline $\begin{array}{l}\text { Aspartate } \\
\text { aminotransferase } \\
\text { (ASP) }\end{array}$ & .054 & *.057 & Muscular pain & .0885438 & 0.466 \\
\hline $\begin{array}{l}\text { Alanine } \\
\text { aminotransferase } \\
\text { (ALT) }\end{array}$ & .047 & *.097 & $\begin{array}{l}\text { Gastrointestinal } \\
\text { complications }\end{array}$ & -.20181 & *0.179 \\
\hline Albumin & .024 & .394 & Headache & -.0297449 & 0.831 \\
\hline Glucose & .017 & .552 & Vomit & .0525788 & 0.696 \\
\hline
\end{tabular}




\begin{tabular}{|llllll|}
\hline Variables & $\begin{array}{l}\text { Pearson } \\
\text { Correlation }\end{array}$ & $\begin{array}{l}\text { P- } \\
\text { value }\end{array}$ & Variables & $\begin{array}{l}\text { Pearson } \\
\text { Correlation }\end{array}$ & P-value \\
\hline $\begin{array}{l}\text { Lactate } \\
\text { dehydrogenase (LDH) }\end{array}$ & .056 & $* .049$ & Nausea & .0083105 & 0.949 \\
\hline $\begin{array}{l}\text { Activated partial } \\
\text { thromboplastin time }\end{array}$ & -.036 & .213 & $\begin{array}{l}\text { Erythrocyte } \\
\text { sedimentation rate } \\
\text { (ESR) }\end{array}$ & .040 & $* .157$ \\
\hline Prothrombin time & .010 & .714 & $\begin{array}{l}\text { Hyper sensitive } \\
\text { troponin }\end{array}$ & -.2146846 & 0.439 \\
\hline Alkaline phosphatase & -.003 & .929 & C reactive protein & .0258788 & $* 0.196$ \\
\hline
\end{tabular}

After feature selection, the 20 diagnostic criteria acquired the determined correlation coefficient at $\mathrm{P}<0.2$. These variables include age, creatinine, white-cell count, lymphocyte /neutrophil count, BUN, ASP, ALT, LDH, activated partial thromboplastin time, cough, hypertension, cardiovascular disorders, diabetes, dyspnea, oxygen therapy, pneumonia, GI complications, ESR, and C-reactive protein, introduced as the most significant features (predictors) to predict hospital LOS.

\subsection{Determining the appropriate configuration for the MLP}

To select the best predictive performance, different networks with multiple configurations were trained and their performance was compared according to a series of tests and training data. Tables 5 and 6 list the RMSE rate of each network with the number of different neurons in the hidden layers for both data sets. These results are also shown in Figure 2.

Table5. The RMSE of each ANN network for whole features 


\begin{tabular}{|lllllll|}
\hline Train algorithm & $\mathbf{5}$ & $\mathbf{1 0}$ & $\mathbf{1 5}$ & $\mathbf{2 0}$ & $\mathbf{2 5}$ & $\mathbf{3 0}$ \\
& neurons & neurons & neurons & neurons & neurons & neurons \\
\hline Levenberg-Marquardt & 2.3338 & 2.3825 & 2.4444 & 2.3863 & 2.3782 & 3.0873 \\
\hline Bayesian Regularization & 1.9291 & 1.732 & 1.6963 & 1.6213 & 1.9454 & 1.8312 \\
\hline $\begin{array}{l}\text { BFGS quasi-Newton } \\
\text { backpropagation }\end{array}$ & 2.3948 & 2.3701 & 2.3726 & 2.3932 & 2.2855 & 2.2507 \\
\hline Resilient Backpropagation & 2.3513 & 2.3365 & 2.4433 & 2.6511 & 3.2506 & 2.8938 \\
\hline Scaled Conjugate Gradient & 2.4085 & 2.4049 & 2.3882 & 2.3791 & 2.3944 & 2.322 \\
\hline $\begin{array}{l}\text { Conjugate Gradient with } \\
\text { Powell/Beale Restarts }\end{array}$ & 2.3927 & 2.4045 & 2.4045 & 2.4301 & 2.3861 & 2.3365 \\
\hline $\begin{array}{l}\text { Fletcher-Powell Conjugate } \\
\text { Gradient }\end{array}$ & 2.4015 & 2.3845 & 2.3936 & 2.3581 & 2.3642 & 2.319 \\
\hline $\begin{array}{l}\text { Polak-Ribiére Conjugate } \\
\text { Gradient }\end{array}$ & 2.3966 & 2.3989 & 2.4514 & 2.4038 & 2.3545 & 2.7662 \\
\hline $\begin{array}{l}\text { One Step Secant } \\
\text { Variable Learning Rate Gradient }\end{array}$ & 2.405 & 2.3985 & 2.8746 & 2.8096 & 2.6103 & 2.9711 \\
\hline Descent & 16.0903 & 23.6745 & 26.0844 & 25.2706 & 32.1784 & 41.2996 \\
\hline $\begin{array}{l}\text { Gradient Descent with } \\
\text { Momentum }\end{array}$ & 16.896 & 42.1661 & 36.6554 & 30.9327 & 26.1043 & 29.3946 \\
\hline \begin{tabular}{l} 
Gradient Descent \\
\hline
\end{tabular} & 2.3924 & 2.4454 & 2.4101 & 2.5861 & 2.8005 \\
\hline
\end{tabular}

Table6. The RMSE of each ANN network for selected features 


\begin{tabular}{|c|c|c|c|c|c|c|}
\hline Train algorithm & $\begin{array}{l}5 \\
\text { neurons }\end{array}$ & $\begin{array}{l}10 \\
\text { neurons }\end{array}$ & $\begin{array}{l}15 \\
\text { neurons }\end{array}$ & $\begin{array}{l}20 \\
\text { neurons }\end{array}$ & $\begin{array}{l}25 \\
\text { neurons }\end{array}$ & $\begin{array}{l}30 \\
\text { neurons }\end{array}$ \\
\hline Levenberg-Marquardt & 2.3617 & 2.4407 & 2.3937 & 2.3346 & 2.3564 & 2.4074 \\
\hline Bayesian Regularization & 2.3386 & 2.2332 & 2.3493 & 2.2995 & 2.2965 & 2.2962 \\
\hline $\begin{array}{l}\text { BFGS quasi-Newton } \\
\text { backpropagation }\end{array}$ & 2.3756 & 2.3388 & 2.3847 & 2.3284 & 2.8562 & 2.757 \\
\hline Resilient Backpropagation & 2.3998 & 2.3869 & 2.4774 & 2.7853 & 3.296 & 2.7826 \\
\hline Scaled Conjugate Gradient & 2.5182 & 2.4187 & 2.3952 & 2.9402 & 2.3695 & 2.4256 \\
\hline $\begin{array}{l}\text { Conjugate Gradient with } \\
\text { Powell/Beale Restarts }\end{array}$ & 2.3895 & 2.372 & 2.3759 & 2.3617 & 2.3459 & 2.3962 \\
\hline $\begin{array}{l}\text { Fletcher-Powell Conjugate } \\
\text { Gradient }\end{array}$ & 2.3851 & 2.4322 & 2.4218 & 2.4023 & 2.3655 & 2.4033 \\
\hline $\begin{array}{l}\text { Polak-Ribiére Conjugate } \\
\text { Gradient }\end{array}$ & 2.4646 & 2.4124 & 2.4607 & 2.3935 & 2.4053 & 2.4818 \\
\hline One Step Secant & 2.3997 & 2.3854 & 2.4639 & 2.4297 & 2.5942 & 2.353 \\
\hline $\begin{array}{l}\text { Variable Learning Rate Gradient } \\
\text { Descent }\end{array}$ & 2.4135 & 2.4264 & 2.5287 & 2.9861 & 3.3325 & 3.6619 \\
\hline $\begin{array}{l}\text { Gradient Descent with } \\
\text { Momentum }\end{array}$ & 13.7549 & 17.353 & 46.4296 & 33.9491 & 27.4377 & 54.9474 \\
\hline Gradient Descent & 9.1643 & 18.8733 & 50.1962 & 53.7368 & 25.1357 & 61.4867 \\
\hline
\end{tabular}

According to Figure 2, using a total of 53 risk factors, the best results were obtained by the neural network with 20 neurons in the hidden layer and the Bayesian Regularization training algorithm. The RMSE of this technique is 1.6213 , which has the lowest error rate among the designed networks. This Figure also shows the neural network with Bayesian Regularization training algorithm based on selected risk factors $(n=20)$ with 10 neurons achieving the best result (RMSE $=2.2332)$. Error histogram for the Bayesian Regularization training algorithm is depicted in Figure 3.

According to Figure 3, although the error rate in the dataset with selected features is higher, the error distribution is better and for small samples, it indicates an error of more than 3 days. Network architecture for the Bayesian Regularization training algorithm based on the whole data set is shown in Figure 4.

Finally, the Bayesian Regularization of 20 neurons user interface was designed by Visual Studio 2018 application software (Fig. 5).

\section{Discussion}


In the COVID-19 pandemic, the LOS is considered as one of the basic measures to assess the performance of healthcare quality services and care planning (43). The exact prediction of LOS can support the bed administration and project future requirements for optimal medical resource allocation. However, LOS may be affected by many elements and may be challenging, especially in complex, novel, and ambiguous medical conditions such as the current COVID-19 crisis $(10,11)$. While statistical approaches have been applied to forecast hospital LOS but using ML algorithms is proven to have more optimal performance(44). Therefore, healthcare industries and clinicians worldwide adopted various ML algorithms to resolve some LOS prediction uncertainties(45).

Determining the best network training algorithm depends on many circumstances, including, the complexity of the problems, the number of data in the training set, the number of weights and biases in the network, the error goal, and whether the network is used to identify the pattern or to estimate the function(46). The current study aims to retrospectively develop and validate ANNs based on the most affecting variables on the LOS. Toward this aim, 12 ANN models were developed by using only deidentified clinical data of confirmed COVID-19 patients that would be available at the time of admission.

Levenberg-Marquardt -based algorithms have the best performance in estimating the functions. If the weight number is low, it will converge more quickly and has a very less error rate than other networks. But when the weight number increases, its efficiency decreases $(47,48)$. Conjugate Gradient-based algorithms also have satisfactory performance in estimating the functions and pattern recognition. Furthermore, their efficiency would not reduce significantly with an increase in the weight number (49, 50). In the present study, algorithms based on Levenberg-Marquardt and Conjugate Gradient have had a satisfactory performance. The resilient Backpropagation method has had undesirable performance in function estimation compared to other algorithms because it demonstrated better capability for pattern recognition $(51,52)$. The BFGS quasi-Newton back-propagation works similar to Levenberg-Marquardt and its computation is required not to affect geometrically the size of the network because the inverse matrix must be calculated for each iteration. The variable learning rate algorithm had a slow convergence and the other two Gradient Descent-based algorithms (Gradient Descent with Momentum and Gradient Descent), as shown in this study, do not perform well in estimating the functions $(53,54)$.

Bayesian Regularization updates network weights and biases based on the Levenberg-Marquardt optimization method. This method minimizes the combination of squares error and weights and seeks the right combination that leads to a network with high generalizability $(55,56)$. Since Bayesian regularization is looking for a network with high generalizability, so the best results have been obtained by this algorithm. The experimental results showed that Bayesian Regularization yielded the best performance compared to other techniques in the LOS prediction for COVID-19 patients (RSME of 1.6213 (layer 20) and 2.2332 (layer10) for whole and selected features respectively). So far, most efforts have been targeted the ANN application for LOS prediction. Neto (2020) attempted to predict the LOS for stroke patients, finally, the ANN gained the best result with RMSE and an MAE of 5.9451 and 4.6354, respectively(28). Maharlou (2020) showed adaptive neuro-fuzzy algorithm (with mean squared error [MSE] $=7$ and $\mathrm{R}=0.88$ ) is outperformed than ANN (with MSE $=21$ and $\mathrm{R}=0.60$ ) to prediction LOS in ICU 
patients(57). Launay (2015) compared two feeds forward ANNs such MLP and modified MLP for predicting prolonged LOS and the best performance was reported with the modified MLP with a sensitivity of $62.7 \%$, specificity of $96.6 \%$, and AUROC of $90.5 \%(58)$. Morton (2014) dedicated the most successful results are obtained by using the ANN technique with RMSE of 5.9451 and Mean Absolute Error (MAE) of 4.6354 to predict the LOS of hospitalized diabetic patients (27). Kulkarin (2021) designed an MLP-based model for predicting prolonged LOS of coronary patients with an accuracy of $90.87 \%(26)$. Similarly in another work by Bacchi et al. (2019) showed that the MLP achieved the highest accuracy on prediction of LOS with MAE (0.246), RMSE (0.369), and AUC (0.864)(59). Kabir (2019) and Hijjry (2020) developed a prediction model to anticipation LOS and the results presented that back propagation neural network with an accuracy of $92.58 \%$ and $78.29 \%$ respectively, outperformed all other models in these studies $(24,25)$. East's $(2020)$ results showed that the model developed with ANN yielded the best performance to predict long LOS (AUC with $0.9760 \%$ )(60). In our research, the best performance was obtained by the neural network with 20 neurons in the hidden layer of the Bayesian Regularization classifier with RMSE of 1.6213 for the whole dataset and the neural network with 10 neurons in the hidden layer of Bayesian Regularization classifier with RMSE of 2.2332 for selected features. Although the Bayesian Regularization algorithm achieved the best results, the model training was very slow and time-consuming. Before conducting feature selection $(n=54)$, the average result was obtained at epoch $=$ 456 and after feature selection $(n=20)$ at epoch $=411$.

In the bibliography, many studies have been undertaken to identify the key risk factors for hospital LOS (8, $13-16,61,62)$. The top clinical variables affecting longer LOS in reviewed studies including: age (older age $^{(13,15,16,62)}$, comorbidities $^{(8,14,61,62)}$ (cardiovascular, hypertension, diabetes, respiratory diseases such asthma or COPD), loss of consciousness $(8,14,62)$, increased BUN ${ }^{(8,14-16)}$, leukocytosis ${ }^{(8,61)}$,

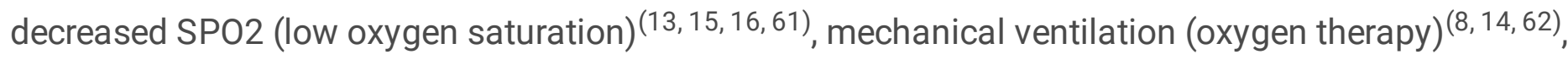
pleural effusion $(13,15,61)$, dry cough ${ }^{(13,62)}$, and fever $(8,15,16,62)$. In the present study, the most important variables ( $n=20$ predictors) were identified through correlation coefficient at the level of $P$-value $<0.2$ (feature selection). These variables include age, creatinine, white-cell count, lymphocyte/neutrophil count, BUN, ASP, ALT, LDH, activated partial thromboplastin time, cough, hypertension, cardiovascular disorders, diabetes, dyspnea, oxygen therapy, pneumonia, GI complications, ESR, and C-reactive protein. In general, high compliance was observed from the results of classifying and prioritizing variables in reviewed studies with the most common variables in the current study.

Finally, accurate prediction LOS provides a better plan for hospital administrators and clinicians in order to improve patient quality of care(63). The results of the current study illustrated that the designed ANN model can appropriately predict the COVID-19 LOS by using clinical variables that are readily available in the hospital data registry.

\section{Limitations}

This study had some limitations that are necessary to be recognized. First, we deal with a retrospective dataset that may suffer from uneven or imbalanced, noisy, duplicates, and meaningless values, which 
may result in prejudice in the predictions. Thus, we balanced them by eliminating data as much as possible from the dataset. Second, this study was conducted at a single center and only based on 1225 data, so the results may not be deduced and may also confine the generalizability of the proposed model; moreover, we only used ANN algorithms for prediction analyses, but other algorithms may perform better. The lack of an integrated registry system with $M L$ models and manual data entry has an undesirable impact on data mining performance. Lastly, the registry dataset lacks some diagnostic criteria such as radiological indicators. In the future, the performance of our computational model will be improved if we test more ML techniques at prospective, multicenter, and qualitative datasets.

But the model is inputted with a slight number of features (20 features), yet provides a precise calculation of the LOS. Moreover, the developed model can provide successfully forecast the LOS using data from multicenter settings, in a longer period, apply for more ML methods, and extract the features affecting it among various types of patients. Thus, the model is simple, correct, and can be effortlessly implemented in practice.

\section{Conclusion}

In this study, we have developed and evaluated several ANNs to predict the LOS of COVID-19 patients using baseline and selected clinical variables (53 and 20 risk factors respectively). The results revealed that ANNs can provide high performance for predicting LOS. It has been observed that the Bayesian Regularization model performed best on classification accuracy better than the other ANN algorithms. Estimating the LOS of patients hospitalized with COVID-19 is crucial for effectively planning the bed management along with related personnel and facilities requirements. In addition, it is expected to provide an objective, measurable and evidence-based system to predict COVID-19 LOS and optimize the use of limited hospital resources.

\section{Declarations}

\section{Ethics approval and consent to participate}

This article is extracted from a research project supported by the Abadan University of Medical Sciences (IR.ABADANUMS.REC.1399.222). All methods of the present study were performed in accordance with the relevant guidelines and regulations of the ethical committee of Abadan Faculty of Medical Sciences (research.ac.ir). Our study is not a human study.In this study, we used the medical documentation of hospitalization patients in the hospital. To do this, we obtained permission from the ethics committee of Abadan University of Medical Sciences and, with the coordination of the hospital, accessed the patients' medical records.

\section{Consent for publication}

Not applicable. 
Availability of data and materials

All data generated and analyzed during the current study are not publicly available but are available from the corresponding author on reasonable request and the Student Research Committee of Abadan University of Medical Sciences approval.

\section{Competing interests}

The authors declare that they have no competing interests.

\section{Funding}

There was no funding for this research project.

\section{Authors' contributions}

Hadi Kazemi-Arpanahi, Mostafa Shanbehzadeh: Conceptualization; Data curation; Formal analysis; Investigation; Software; Roles/Writing - original draft.

Azam Orooji Mohsen Shafiee, Hadi Kazemi-Arpanahi: Conceptualization; Formal analysis; Investigation; Roles/Writing - original draft; Funding acquisition; Methodology; Project administration; Resources; Supervision; Writing - review \& editing.

Azam Orooji, Mostafa Shanbehzadeh, Hadi Kazemi-Arpanahi: Conceptualization; Investigation; Methodology; Validation; Writing - review \& editing.

\section{Acknowledgments}

We thank the Research Deputy of the Abadan University of Medical Sciences for financially supporting this project.

\section{References}

1. Liu Y, Wang Z, Ren J, Tian Y, Zhou M, Zhou T, et al. A COVID-19 Risk Assessment Decision Support System for General Practitioners: Design and Development Study. Journal of medical Internet research. 2020;22(6):e19786.

2. Alom MZ, Rahman M, Nasrin MS, Taha TM, Asari VK. COVID_MTNet: COVID-19 Detection with MultiTask Deep Learning Approaches. arXiv preprint arXiv:200403747. 2020.

3. Bansal A, Padappayil RP, Garg C, Singal A, Gupta M, Klein A. Utility of Artificial Intelligence Amidst the COVID 19 Pandemic: A Review. Journal of Medical Systems. 2020;44(9).

4. Lai C-C, Shih T-P, Ko W-C, Tang H-J, Hsueh P-R. Severe acute respiratory syndrome coronavirus 2 (SARS-CoV-2) and coronavirus disease-2019 (COVID-19): The epidemic and the challenges. International 
Journal of Antimicrobial Agents. 2020;55(3):105924.

5. Hussain A, Bhowmik B, do Vale Moreira NC. COVID-19 and diabetes: Knowledge in progress. Diabetes Research and Clinical Practice. 2020;162.

6. Moujaess E, Kourie HR, Ghosn M. Cancer patients and research during COVID-19 pandemic: A systematic review of current evidence. Critical Reviews in Oncology/Hematology. 2020;150:102972.

7. Yadaw AS, Li Y-C, Bose S, lyengar R, Bunyavanich S, Pandey G. Clinical features of COVID-19 mortality: development and validation of a clinical prediction model. The Lancet Digital Health. 2020;2(10):e516-e25.

8. Hong Y, Wu X, Qu J, Gao Y, Chen H, Zhang Z. Clinical characteristics of coronavirus disease 2019 and development of a prediction model for prolonged hospital length of stay. Annals of translational medicine. 2020;8(7).

9. Daghistani TA, Elshawi R, Sakr S, Ahmed AM, Al-Thwayee A, Al-Mallah MH. Predictors of in-hospital length of stay among cardiac patients: A machine learning approach. International journal of cardiology. 2019;288:140-7.

10. Dan T, Li Y, Zhu Z, Chen X, Quan W, Hu Y, et al., editors. Machine Learning to Predict ICU Admission, ICU Mortality and Survivors' Length of Stay among COVID-19 Patients: Toward Optimal Allocation of ICU Resources. 2020 IEEE International Conference on Bioinformatics and Biomedicine (BIBM); 2020: IEEE.

11. Wu C, Glass S, Demars S, Tulloch-Palomino LG, Wander PL. Estimated excess acute-care length of stay and extra cost of testing-based versus symptom-based isolation strategies among veterans hospitalized with coronavirus disease 2019 (COVID-19) discharging to a congregate setting. Infection control and hospital epidemiology. 2020:1-3.

12. Ayyoubzadeh SM, Ghazisaeedi M, Kalhori SRN, Hassaniazad M, Baniasadi T, Maghooli K, et al. A study of factors related to patients' length of stay using data mining techniques in a general hospital in southern Iran. Health information science and systems. 2020;8(1):1-11.

13. Jang SY, Seon J-Y, Yoon S-J, Park S-Y, Lee SH, Oh I-H. Comorbidities and Factors Determining Medical Expenses and Length of Stay for Admitted COVID-19 Patients in Korea. Risk Management and Healthcare Policy. 2021;14.

14. Thiruvengadam G, Lakshmi M, Ramanujam R. A Study of Factors Affecting the Length of Hospital Stay of COVID-19 Patients by Cox-Proportional Hazard Model in a South Indian Tertiary Care Hospital. Journal of Primary Care \& Community Health. 2021;12:21501327211000231.

15. Wu S, Xue L, Legido-Quigley $\mathrm{H}, \mathrm{Khan} \mathrm{M}, \mathrm{Wu} \mathrm{H}$, Peng $\mathrm{X}$, et al. Understanding factors influencing the length of hospital stay among non-severe COVID-19 patients: A retrospective cohort study in a Fangcang shelter hospital. PloS one. 2020;15(10):e0240959. 
16. Alwafi H, Naser AY, Qanash S, Brinji AS, Ghazawi MA, Alotaibi B, et al. Predictors of Length of Hospital Stay, Mortality, and Outcomes Among Hospitalised COVID-19 Patients in Saudi Arabia: A CrossSectional Study. Journal of Multidisciplinary Healthcare. 2021;14:839.

17. Calman YB-L, Gelbshtein U, Liverant-Taub S, Ziv A, Eytan D, Gorfine M, et al. Development and validation of a machine learning model for predicting illness trajectory and hospital resource utilization of COVID-19 hospitalized patients-a nationwide study. 2020.

18. Shanbehzadeh M, Nopour R, Kazemi-Arpanahi H. Comparison of Four Data Mining Algorithms for Predicting Colorectal Cancer Risk. Journal of Advances in Medical and Biomedical Research.29(133):1008.

19. Nassif AB, Azzeh M, Banitaan S, Neagu D. Guest editorial: special issue on predictive analytics using machine learning. Springer; 2016.

20. Hernandez-Suarez DF, Ranka S, Kim Y, Latib A, Wiley J, Lopez-Candales A, et al. Machine-learningbased in-hospital mortality prediction for transcatheter mitral valve repair in the United States. Cardiovascular Revascularization Medicine. 2020.

21. Shanbehzadeh M, Nopour R, Kazemi-Arpanahi H. Comparison of Four Data Mining Algorithms for Predicting Colorectal Cancer Risk. Journal of Advances in Medical and Biomedical Research. 2021;29(133):100-8.

22. Streun GL, Elmiger MP, Dobay A, Ebert L, Kraemer T. A machine learning approach for handling big data produced by high resolution mass spectrometry after data independent acquisition of small molecules - Proof of concept study using an artificial neural network for sample classification. Drug testing and analysis. 2020;12(6):836-45.

23. Yang $\mathrm{H}$, Zhang Z, Zhang J, Zeng XC. Machine learning and artificial neural network prediction of interfacial thermal resistance between graphene and hexagonal boron nitride. Nanoscale. 2018;10(40):19092-9.

24. Hijry H, Olawoyin R, editors. Application of Machine Learning Algorithms for Patient Length of Stay Prediction in Emergency Department During Hajj. 2020 IEEE International Conference on Prognostics and Health Management (ICPHM); 2020: IEEE.

25. Kabir S, Farrokhvar L, editors. Non-Linear Feature Selection for Prediction of Hospital Length of Stay. 2019 18th IEEE International Conference On Machine Learning And Applications (ICMLA); 2019: IEEE.

26. Kulkarni $\mathrm{H}$, Thangam M, Amin AP. Artificial neural network-based prediction of prolonged length of stay and need for post-acute care in acute coronary syndrome patients undergoing percutaneous coronary intervention. European Journal of Clinical Investigation. 2021;51(3):e13406. 
27. Morton A, Marzban E, Giannoulis G, Patel A, Aparasu R, Kakadiaris IA, editors. A comparison of supervised machine learning techniques for predicting short-term in-hospital length of stay among diabetic patients. 2014 13th International Conference on Machine Learning and Applications; 2014: IEEE.

28. Neto C, Brito M, Peixoto H, Lopes V, Abelha A, Machado J, editors. Prediction of length of stay for stroke patients using artificial neural networks. World Conference on Information Systems and Technologies; 2020: Springer.

29. Karegowda AG, Manjunath A, Jayaram M. Comparative study of attribute selection using gain ratio and correlation based feature selection. International Journal of Information Technology and Knowledge Management. 2010;2(2):271-7.

30. Fazlollahi P, Afarineshkhaki A, Nikbakhsh R. Predicting the Medals of the Countries Participating in the Tokyo 2020 Olympic Games Using the Test of Networks of Multilayer Perceptron (MLP). Annals of Applied Sport Science. 2020;8(4):1-12.

31. Theerthagiri P, Gopala Krishnan C, Nishan AH. Prognostic analysis of hyponatremia for diseased patients using multilayer perceptron classification technique. EAI Endorsed Transactions on Pervasive Health and Technology. 2021;7(26).

32. Shah Z, Raja MAZ, Chu YM, Khan WA, Abbas SZ, Shoaib M, et al. Computational intelligence of Levenberg-Marquardt backpropagation neural networks to study the dynamics of expanding/contracting cylinder for Cross magneto-nanofluid flow model. Physica Scripta. 2021;96(5).

33. Moshkbar-Bakhshayesh K. Bayesian regularization of multilayer perceptron neural network for estimation of mass attenuation coefficient of gamma radiation in comparison with different supervised model-free methods. Journal of Instrumentation. 2020;15(11).

34. Ghani NAM, Kamaruddin SA, Ramli NM, Musirin I, Hashim H. Enhanced BFGS quasi-newton backpropagation models on $\mathrm{MCCl}$ data. Indonesian Journal of Electrical Engineering and Computer Science. 2017;8(1):101-6.

35. Saputra W, Tulus T, Zarlis M, Sembiring RW, Hartama D, editors. Analysis Resilient Algorithm on Artificial Neural Network Backpropagation. Journal of Physics: Conference Series; 2017.

36. Aburaed N, Atalla S, Mukhtar H, Al-Saad M, Mansoor W, editors. Scaled conjugate gradient neural network for optimizing indoor positioning system. 2019 International Symposium on Networks, Computers and Communications, ISNCC 2019; 2019.

37. Dawahdeh $\mathrm{M}$, Sulaiman IM, Rivaie M, Mamat $\mathrm{M}$. A new spectral conjugate gradient method with strong wolfe-powell line search. International Journal of Emerging Trends in Engineering Research. 2020;8(2):391-7. 
38. Abid S, Mouelhi A, Fnaiech F, editors. Accelerating the multilayer perceptron learning with the Davidon Fletcher powell algorithm. IEEE International Conference on Neural Networks - Conference Proceedings; 2006.

39. Latif $M$, Herawati S, editors. The application of eemd and neural network based on polak-ribiére conjugate gradient algorithm for crude oil prices forecasting. MATEC web of conferences; 2016: EDP Sciences.

40. Solikhun, Wahyudi M, Safii M, Zarlis M, editors. Backpropagation Network Optimization Using One Step Secant (OSS) Algorithm. IOP Conference Series: Materials Science and Engineering; 2020.

41. Lu Y, Li W, Wang H. A Batch Variable Learning Rate Gradient Descent Algorithm with the Smoothing L1/2 Regularization for Takagi-Sugeno Models. IEEE Access. 2020;8:100185-93.

42. Xue H, Shao Z, Sun H. Data classification based on fractional order gradient descent with momentum for RBF neural network. Network: Computation in Neural Systems. 2020.

43. Lapidus N, Zhou X, Carrat F, Riou B, Zhao Y, Hejblum G. Biased and unbiased estimation of the average length of stay in intensive care units in the Covid-19 pandemic. Annals of intensive care. 2020;10(1):135.

44. Bacchi S, Tan Y, Oakden-Rayner L, Jannes J, Kleinig T, Koblar S. Machine Learning in the Prediction of Medical Inpatient Length of Stay. Internal medicine journal. 2020.

45. Symum H, Zayas-Castro JL. Prediction of Chronic Disease-Related Inpatient Prolonged Length of Stay Using Machine Learning Algorithms. Healthc Inform Res. 2020;26(1):20-33.

46. . .!! INVALID CITATION !!! (3-5).

47. Amellas $\mathrm{Y}$, Djebli A, Echchelh A. Levenberg-marquardt training function using on mlp, rnn and elman neural network to optimize hourly forecasting in tetouan city (Northern Morocco). Journal of Engineering Science and Technology Review. 2020;13(1):67-71.

48. Miaoli M, Xiaolong W, Honggui $\mathrm{H}$, editors. Accelerated Levenberg-Marquardt Algorithm for Radial Basis Function Neural Network. Proceedings - 2020 Chinese Automation Congress, CAC 2020; 2020.

49. ColaÇo MJ, Orlande HRB. Comparison of different versions of the conjugate gradient method of function estimation. Numerical Heat Transfer; Part A: Applications. 1999;36(2):229-49.

50. Jeong SB, Lee SJ, Park GJ. Improvement of the convergence capability of a single loop single vector approach using conjugate gradient for a concave function. Transactions of the Korean Society of Mechanical Engineers, A. 2012;36(7):805-11. 
51. Dutta M, Chatterjee A, Rakshit A, editors. A resilient backpropagation neural network based phase correction system for automatic digital AC bridges. CPEM Digest (Conference on Precision Electromagnetic Measurements); 2004.

52. Wang $X$, Wang $H$, Dai G, Tang Z. A reliable resilient backpropagation method with gradient ascent. Lecture Notes in Computer Science (including subseries Lecture Notes in Artificial Intelligence and Lecture Notes in Bioinformatics)2006. p. 236-44.

53. Sotirov S, Atanassov K, Krawczak M. Generalized net model for parallel optimization of feedforward neural network with variable learning rate backpropagation algorithm with time limit. Studies in Computational Intelligence2010. p. 361-71.

54. Yu F, Hu Z, editors. Variable weighted learning algorithm and its convergence rate. 5th International Conference on Natural Computation, ICNC 2009; 2009.

55. Khan I, Raja MAZ, Shoaib M, Kumam P, Alrabaiah H, Shah Z, et al. Design of Neural Network with Levenberg-Marquardt and Bayesian Regularization Backpropagation for Solving Pantograph Delay Differential Equations. IEEE Access. 2020;8:137918-33.

56. Priya A, Garg S. A Comparison of Prediction Capabilities of Bayesian Regularization and Levenberg-Marquardt Training Algorithms for Cryptocurrencies. Smart Innovation, Systems and Technologies2020. p. 657-64.

57. Maharlou H, Kalhori SRN, Shahbazi S, Ravangard R. Predicting length of stay in intensive care units after cardiac surgery: comparison of artificial neural networks and adaptive neuro-fuzzy system. Healthcare informatics research. 2018;24(2):109.

58. Launay $\mathrm{C}$, Rivière $\mathrm{H}$, Kabeshova $\mathrm{A}$, Beauchet $\mathrm{O}$. Predicting prolonged length of hospital stay in older emergency department users: use of a novel analysis method, the Artificial Neural Network. European journal of internal medicine. 2015;26(7):478-82.

59. Bacchi S, Gluck S, Tan Y, Chim I, Cheng J, Gilbert T, et al. Prediction of general medical admission length of stay with natural language processing and deep learning: a pilot study. Internal and emergency medicine. 2020;15(6):989-95.

60. East A, Ray S, Pope R, Cortina-Borja M, Sebire NJ. 45 Predicting long length of stay in a paediatric intensive care unit using machine learning. BMJ Publishing Group Ltd; 2020.

61. ÇETIN Ş, ULGEN A, ŞIVGIN H, Wentian L. A Study on Factors Impacting Length of Hospital Stay of COVID-19 Inpatients. Journal of Contemporary Medicine.11(3 (Forthcoming Issue-Gelecek Sayı)):396404.

62. Guo A, Lu J, Tan H, Kuang Z, Luo Y, Yang T, et al. Risk factors on admission associated with hospital length of stay in patients with COVID-19: a retrospective cohort study. Scientific Reports. 2021;11(1):1-7. 
63. Afshar S, Warden E, Manochehri H, Saidijam M. Application of artificial neural network in miRNA biomarker selection and precise diagnosis of colorectal cancer. Iranian biomedical journal. 2019;23(3):175-83.

\section{Figures}

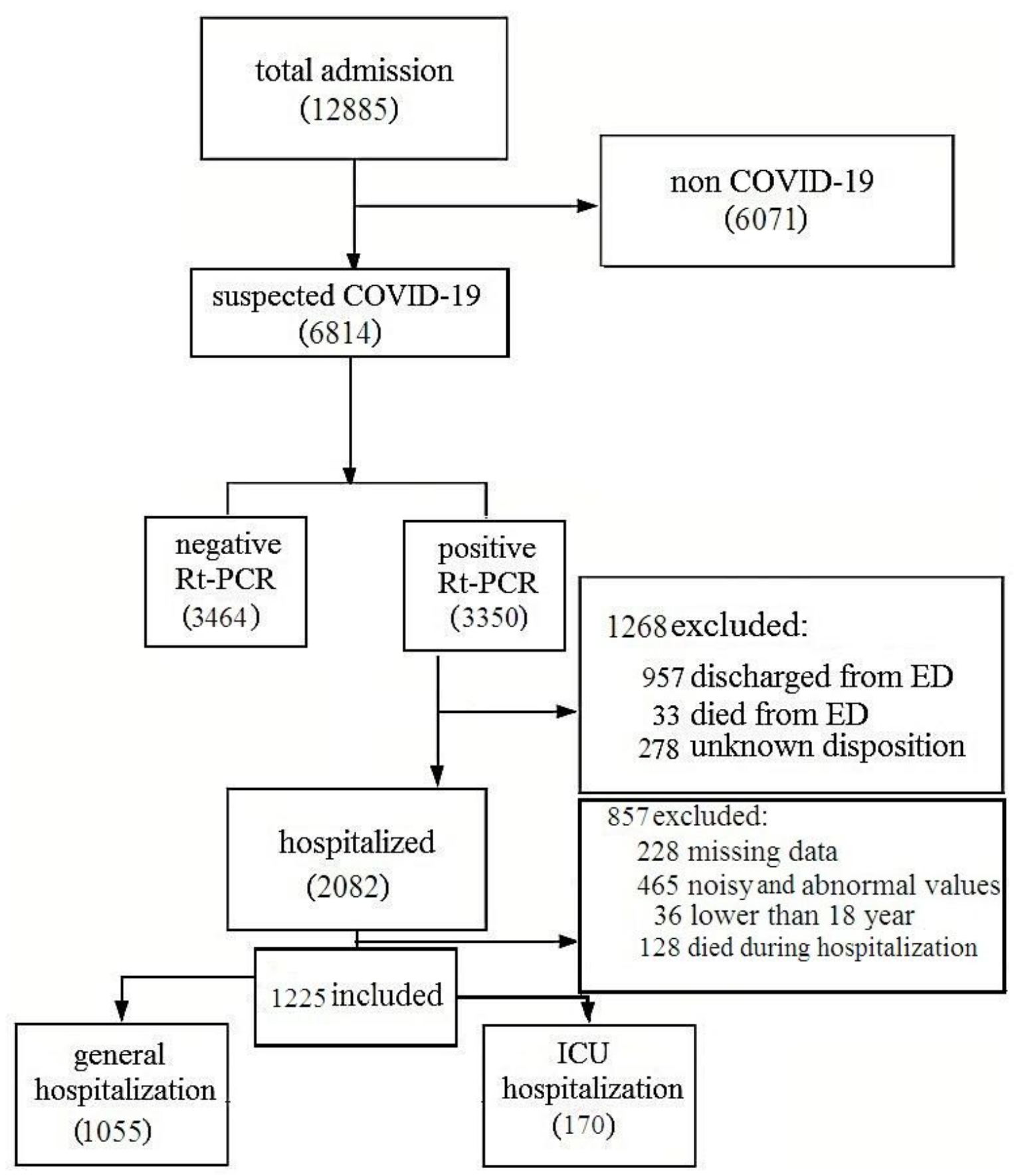


Flow chart describing patient selection

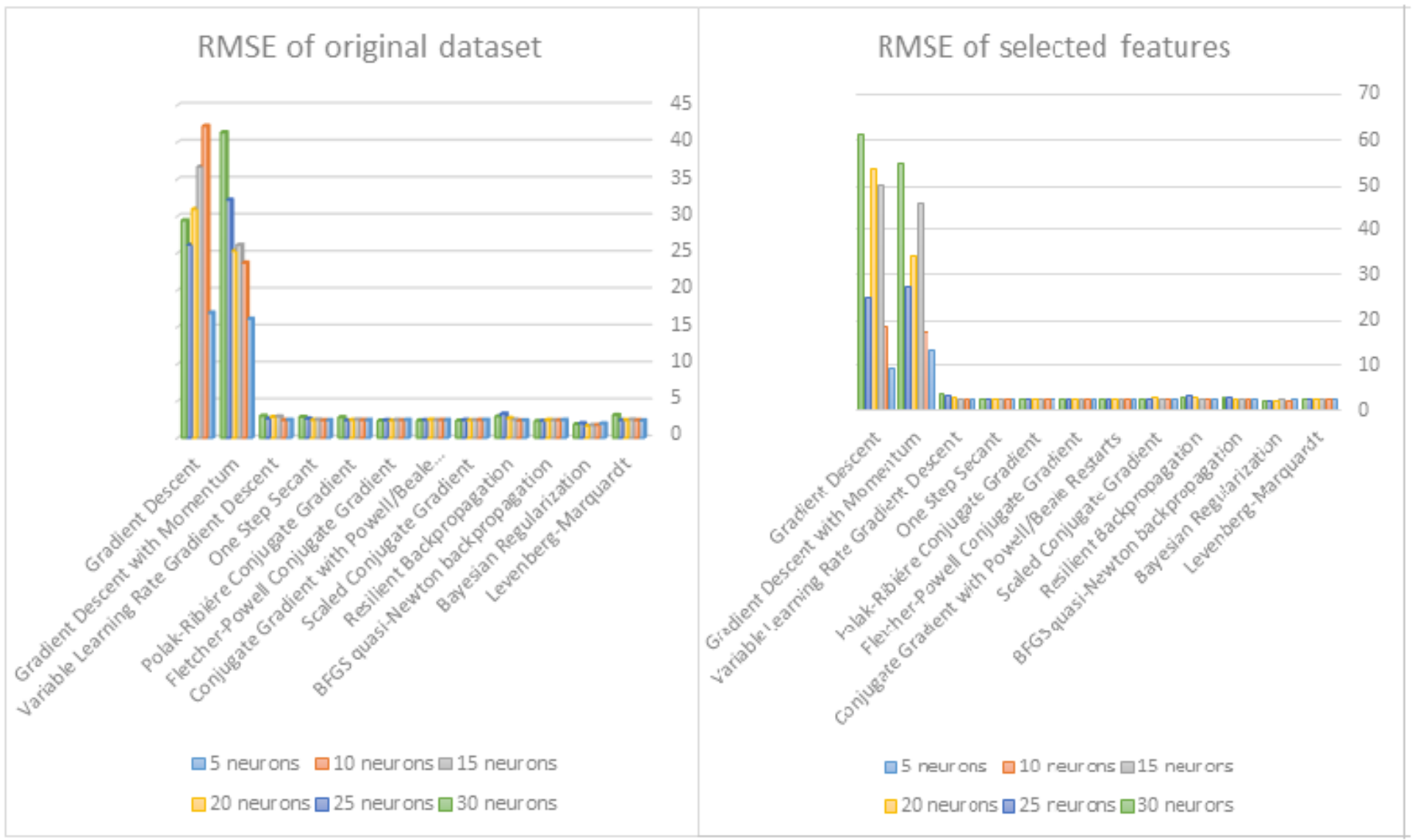

Figure 2

The RMSE rate of both dataset

\begin{tabular}{l|l}
\hline \\
Risk factor set: a selected risk factor
\end{tabular}




\section{Figure 3}

Error histogram for the best model

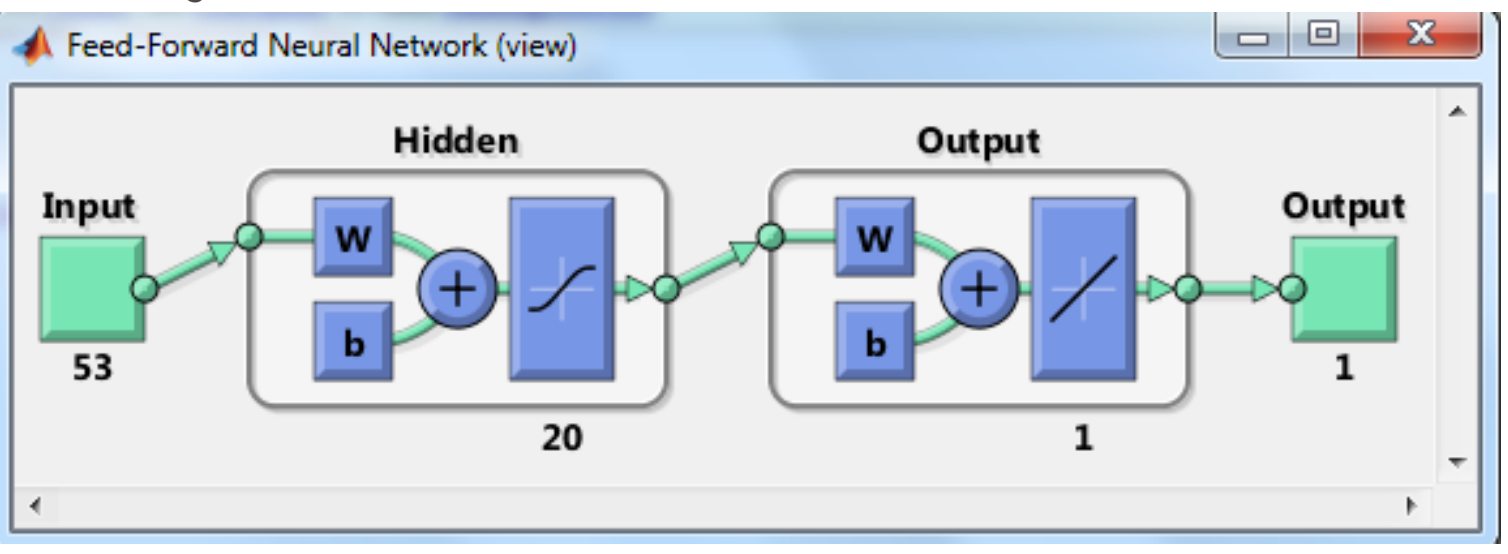

\section{Figure 4}

The architecture of Bayesian Regularization of 20 neurons used for COVID-19 LOS anticipation

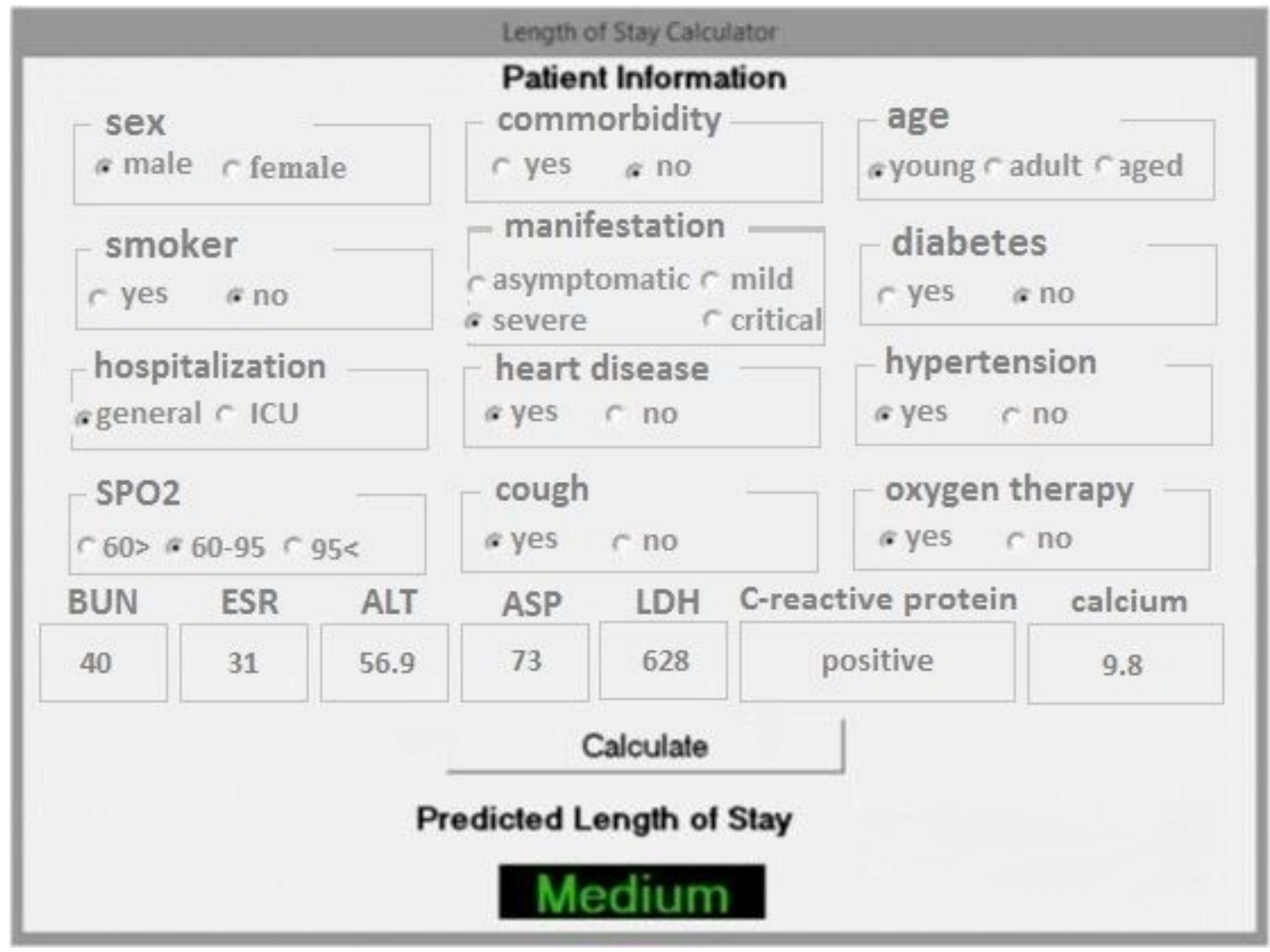

\section{Figure 5}

The user interface of the clinical decision support system 